\title{
Digametic sex determination in the marine polychaete, Capitella capitata (species type I)
}

\author{
Peter S. Petraitis
}

Biology Department, University of Pennsylvania, Philadelphia, PA 19104, USA.

\begin{abstract}
Sex determination in the polychaete, Capitella capitata (species type I), is thought to be a polygenic trait. Since males can be induced to develop into hermaphrodites, crosses were done to examine the effect of the maternal parent on sex ratio. Female $\times$ male crosses produce a 50:50 sex ratio while hermaphrodite $\times$ male crosses produce 97 per cent to 100 per cent males. Differences in sex ratio cannot be explained by sex-specific mortality, and crosses between individuals from different geographical areas give similar results. Sex in this species appears to be determined by digamety with females as the heterogametic sex. Thus hermaphrodite $\times$ male matings should produce all males since hermaphrodites arise from males and are the same genotype (i.e. $\mathrm{ZZ}$ ). Female $(\mathrm{ZW}) \times$ male $(\mathrm{ZZ})$ matings would produce a 50:50 sex ratio. The few females that were produced from a hermaphrodite $\times$ male mating were found to be protogynous hermaphrodites.
\end{abstract}

\section{INTRODUCTION}

Sex determination in polychaete worms is commonly thought to be a polygenic trait (e.g., Bacci, 1965; Schroeder and Hermans, 1975). This view is based on the observations that sex ratios of polychaetes are quite variable, that the expression of sexual phenotypes is very plastic, and that many polychaete species contain not only males and females but also hermaphrodites. The occurrence of hermaphrodites in normally gonochoric species provides an exceptional opportunity for the study of sex determination since crosses between individuals of different sexual phenotypes often give very different sex ratios (e.g., Hauenschild, 1959). Crosses that use individuals with different sexual phenotypes have been widely used by botanists to study sex determination in subdioecious and gynodioecious plants (e.g., Edwardson, 1970; Ganders, 1978; Van Damme, 1983). In animals, individuals in which the wrong sexual phenotype has been induced have been used in a similar fashion (e.g., review by Bacci, 1965), yet surprisingly the technique has been rarely used in hermaphroditic polychaetes.

In this paper I report the results of hermaphrodite $\times$ male and female $\times$ male crosses that were done in a Capitella capitata sibling species.
Sex determination in this species has been reported to be a polygenic trait (Grassle, 1980), yet results of the crosses indicate that sex is determined by a simple system of female heterogamety. This is only the second reported case of simple sex determination in polychaetes.

\section{MATERIALS AND METHODS}

The observations described in this paper are for an unnamed species which has been designated Capitella species type I (Grassle and Grassle, 1976). The species is part of a sibling species complex which was once considered a single, cosmopolitan species, Capitella capitata. Species type $\mathrm{I}$ is normally found in disturbed or polluted marine sediments and dwells in temporary tubes that are constructed of mucous and sediment. Adult worms weigh 3 to $12 \mathrm{mg}$ wet weight (Grassle and Grassle, 1976), although size is highly dependent on the quality of the food (Tenore, 1977). Males reach maturity at a slightly smaller size than their sisters (Petraitis, unpublished data) and have distinct copulatory setae on the eighth and ninth segments. At $15^{\circ} \mathrm{C}$, males develop setae in 45 days while their sisters develop eggs in 49 days; the onset of egg development in females is controlled genetically. 
Heritability, based on a half-sib analysis, is 0.28 (Petraitis, unpublished data).

Fertilisation is internal (Schroeder and Herman's (1975) citation of Eisig's work), and fertilised eggs are attached inside the mothers's tube. First broods average 124 larvae (Petraitis, 1984), and well-fed females can produce a number of broods. Larvae develop from eggs in 10 to 14 days. Most larvae are free-swimming for up to 24 hours but some metamorphose inside the mother's tube.

Capitella species type I has been described as a gonochoric species in which males can secondarily develop ova and function as simultaneous hermaphrodites (Grassle and Grassle, 1976; Holbrook and Grassle, 1984). While many "males" never develop female function to become hermaphrodites, nearly all "male" worms can be induced to develop ova (Petraitis, 1985). For clarity, only worms with both male copulatory setae and eggs will be called hermaphrodites.

If held in isolation or in all-male culture, males will develop eggs quite quickly (Holbrook and Grassle, 1984; Petraitis, 1985). Failure of males to develop into hermaphrodites appears to be genetically controlled (Holbrook and Grassle, 1984). Hermaphrodites can function as either sex (Holbrook, 1982) and rarely self-fertilise (Grassle, 1980). There is evidence that species type $I$ is a diplo-diploid organism and that offspring which are maternally produced by hermaphrodites are the result of sexual reproduction (Holbrook, 1982). Phenotypically, the species is a mixture of males, females and hermaphrodites, and although hermaphrodites are rare in young, large populations, some males will eventually develop into hermaphrodites as the population grows older (citation of Grassle's unpublished data in Holbrook and Grassle, 1984; Petraitis, 1985). The frequency of hermaphrodites in natural populations is difficult to determine since collections often contain several of the sibling species and many individuals are immature. Even so Holbrook and Grassle (1984) report frequencies of 0.3 per cent to 33.3 per cent hermaphrodites for field caught type I animals.

Capitella type I worms used in this study are from Woods Hole, Massachusetts and from Stone Harbour, New Jersey. The Woods Hole animals were collected in 1980; details of the collection are given in Petraitis (1984). These animals have been maintained in culture since that time. The New Jersey worms were collected in September 1983 at the Wetlands Institute in Stone Harbour. It was not known if New Jersey worms were species type
I, thus Capitella from New Jersey were crossed with Woods Hole worms to identify type I individuals. Among the New Jersey worms 13 animals of species type I were found and used as founders of a New Jersey culture.

Mass cultures of type I worms are maintained at $15^{\circ} \mathrm{C}$, and all experiments and crosses are done at $15^{\circ} \mathrm{C}$. I maintain my mass cultures on a regimen of chopped frozen spinach. A small amount of fine sand (less than $300 \mu \mathrm{m}$ ) is added to cultures to facilitate brood tube formation. Further details on maintenance of cultures are given in Petraitis (1984; 1985).

Sex ratio data were obtained from isolated families which were derived from either female $x$ male or hermaphrodite $\times$ male matings. Since sex determination in Capitella type I was reported to be a polygenic trait, crosses with the Woods Hole worms were initially begun to develop pure breeding hermaphroditic and gonochoric lines. For this reason data for the Woods Hole families are from three different sources. The first source was females with brood tubes which were drawn from mass culture; offspring from these broods were denoted parental (i.e., $P$ ) cohorts. Offspring were raised en masse in 4 inch culture bowls until individuals could be sexed. Males were isolated and allowed to develop into hermaphrodites. These hermaphrodites and their sisters provided the maternal parents and were crossed with males that were randomly drawn from mass culture. Offspring from these crosses, denoted as F1, were sexed and served as the second source of families. F1 offspring from female $\times$ male crosses also were used to start a "gonochoric" culture while male offspring from hermaphrodite $\times$ male crosses were used to start a "hermaphroditic" culture. The third source of families are broods which were drawn from these cultures.

Once a brood hatched, sibling larvae were placed into a 4 inch culture bowl. Procedure for maintenance of bowls is identical to methods described in Petraitis $(1984 ; 1985)$. Bowls were kept until all worms had been sexed. All larvae from the parental and F1 matings of Woods Hole animals were raised. In order to control for sexspecific mortality and possible mistakes in sexing, only 25 to 30 siblings were reared per bowl in other matings. In some cases 60 siblings were raised; for these families the offspring were subdivided into two bowls.

For the observations on New Jersey worms, I used families derived from forced matings between females and males or between hermaphrodites and males. Reciprocal crosses between Woods Hole 
and New Jersey worm were also done in this manner.

\section{RESULTS}

Parental and F1 matings for the Woods Hole animals gave very different sex ratios for hermaphrodite $\times$ male and for female $\times$ male matings. The 2110 offspring from the 27 female $\times$ male matings produced 52.9 per cent male offspring. From 31 hermaphrodite $\times$ male matings, 3264 offspring were sexed and 96.7 per cent were male. Three families from the hermaphrodite $\times$ male matings account for 73.1 per cent of the 108 females which I did find in these broods. The sex ratio is very consistent among these families; hermaphrodite mothers produce nearly all males while females produce close to a 50:50 sex ratio.

To control for the possibility of sex-specific mortality, 19 families derived from hermaphrodites and 18 families derived from females were reared using 25 to 30 larvae per bowl. For the analysis no family was used more than once and only bowls with less than 20 per cent mortality were included. For the families from which 60 offspring were reared, the tallies of the two bowls were combined.

For the families that met these criteria, 2 per cent of the offspring from hermaphrodite-derived families are female while in female-derived families 50 per cent of the offspring are female (table 1). In both cases the tests of heterogeneity are not significant and thus it appears that there is no variation in sex ratio among families within type of mating.

Differences in sex ratio cannot be explained by sex-specific mortality of larvae. Overall mortality for all 19 hermaphrodite-derived families is $\mathbf{1 7 . 5}$ per cent and for all 18 female-derived families is $27 \cdot 1$ per cent. A Mann Whitney U-test is not significant; there is no detectable difference in mortality which could account for differences in sex ratio. Sex ratio in the 18 female-derived families is not correlated with the level of mortatlity of larvae (Spearman rank correlation is $+0 \cdot 31$ ). The difference in sex ratio may be due to sex-specific abortion of eggs; however based on data for over 600 broods, no difference is observed in either brood size or number of aborted eggs which could account for the difference in sex ratio (Petraitis, unpublished data).

The most interesting aspect of the hermaphrodite $\times$ male matings is the fate of the six individuals that were scored as females in table 1 . These females are from three families, and all six eventually developed copulatory setae and became hermaphrodies (fig. 1). Since offspring of a family were raised en masse, the transitions shown in fig. 1 represent the minimum number of changes required to explain the census data. It is possible other changes occurred, such as female to male, but these must be balanced by additional transitions of males to hermaphrodites.

From the Woods Hole data, the most parsimonious hypothesis for sex determination is that sex in Capitella type I is a digmetic system in which females are the heterogametic sex. Since hermaphrodites are derived from males, both males and hermaphrodites would be the same genotype (i.e., $\mathrm{ZZ}$ ). Thus a cross between a hermaphrodite and a male would produce all $\mathrm{ZZ}$ offspring. Female $\times$ male and female $x$ hermaphrodite crosses would produce half female ( $\mathrm{ZW})$ and half "male" $(\mathrm{ZZ})$ offspring. I suspect that the occasional female produced by a hermaphrodite $\times$ male mating is in fact a protogynous hermaphrodite and its genotype should be $\mathrm{ZZ}$. This is under investigation.

Additional crosses using both New Jersey and Woods Hole worms are consistent with the hypothesis that females are the heterogametic sex (table 2). First, crosses between females from female-derived broods (i.e., from female $\times$ male matings) and males from hermaphrodite-derived broods produce nearly a 50:50 sex ratio. Second, female $\times$ male and hermaphrodite $\times$ male crosses for New Jersey worms show the same pattern as the Woods Hole animals. Third, reciprocal crosses between New Jersey and Woods Hole worms are as predicted if females are the heterogametic sex. If sex ratio was a polygenic trait, one would expect to see some disruption of sex ratio in these crosses.

Table 1 Numbers of males and females from families derived from females and hermaphrodites.

Number in parentheses are numbers of different families that were used. In all but two families,

25 larvae were isolated and reared (two groups were inadvertently started with 27 larvae). Worms were first sexed at six weeks and rechecked until all had been sexed

\begin{tabular}{|c|c|c|c|c|c|}
\hline \multirow[b]{2}{*}{ Type of Family } & \multicolumn{4}{|c|}{ Number of individuals with } & \multirow{2}{*}{$\begin{array}{l}\text { Mean } \\
\text { mortality }\end{array}$} \\
\hline & Ova & Setae & Both & Neither & \\
\hline Female-derived (8) & 96 & 85 & 0 & 0 & $9 \cdot 5 \%$ \\
\hline Hermaphrodite-derived (13) & 6 & 291 & 0 & 0 & $9.2 \%$ \\
\hline
\end{tabular}




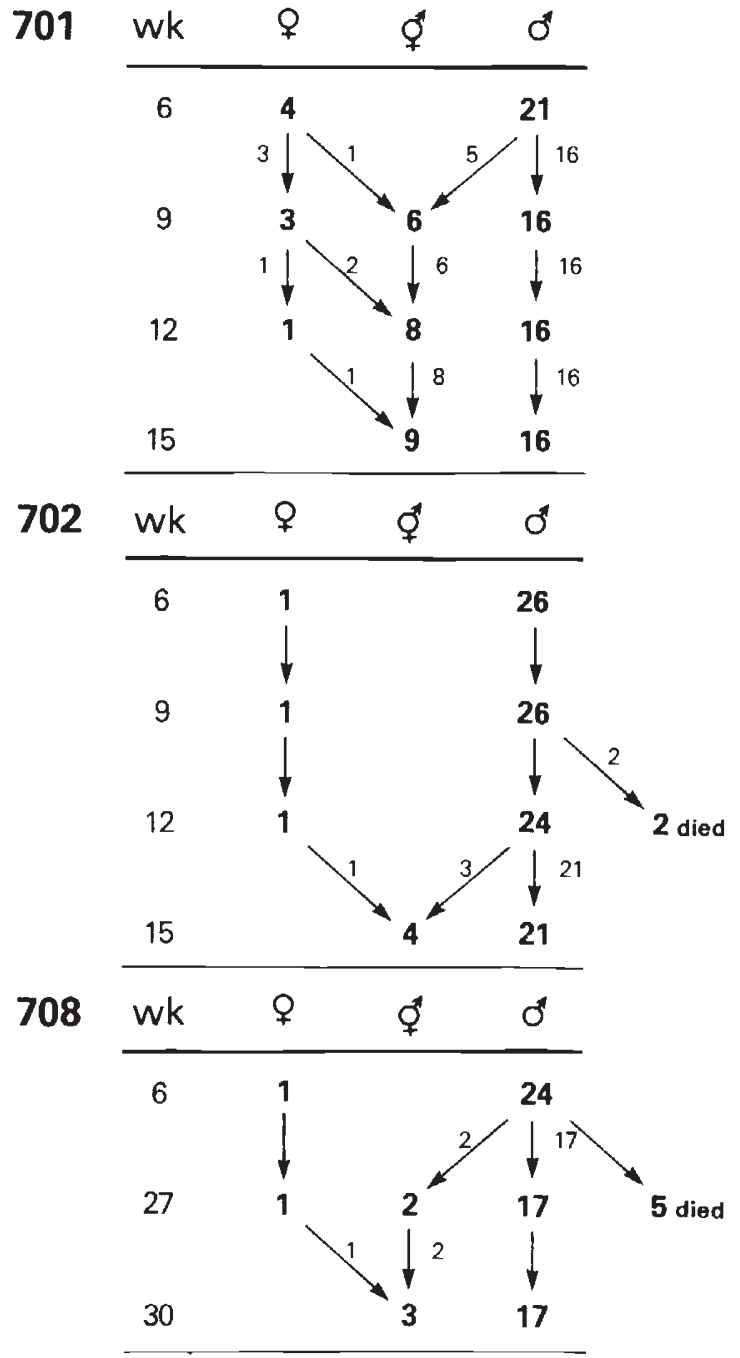

Figure 1 Fate of individuals from the three hermaphroditederived families that contain protogynous worms. The 700 number is the family code. Worms were censused every 3 weeks, and the column labelled age gives the age of the cohort at the time of the census. The corresponding row gives the census results. Presumed transitions are the numbers on the arrows and are the sex changes and deaths that must have occurred to account for differences between successive censuses. Note that the sex chinge transitions are minimum estimates since compensatory changes would not be seen.

\section{DISCUSSION}

Polychaete species show a great deal of variation in sex ratio, and a simple mechanism for sex determination has been described in only one other species of polychaete besides Capitella. Because of the variation in sex ratio and the lack of evidence for a simple mechanism of sex determination, it has been suggested that sex determination in polychaetes is primarily a polygenic trait. In light of what I have found for Capitella, a brief review of the evidence for polygenic control of sex in polychaetes seems warranted. A second and related question is the effect of genetics of sex, such as female heterogamety found in Capitella, on the evolution of hermaphroditism in polychaetes. While hermaphroditism occurs in about 20 families and in over 70 species (Ghiselin, 1969; Schroeder and Hermans, 1975), most zoologists assume a gonochoric ancestor for species that contain a mixture of sexual types. This need not be the case when females are the heterogametic sex (Charlesworth and Charlesworth, 1978).

In Capitella Grassle (1980) reported highly variable sex ratios for families of type I that were raised from single brood tubes. In addition she derived inbred lines which gave a high proportion of males. Holbrook and Grassle (1984) drew the distinction between "high male" and "high female" families that they derived from an unselected culture. Based on these data, they concluded sex determination in Capitella type I must be a polygenic trait.

In fact the high male families show an overall sex ratio of 6.9 per cent females, and the high female families are 54.9 per cent female. The sex ratios are very similar to what I find for hermaphrodite and female-derived families. Since earlier studies (i.e., Grassle, 1980; Holbrook and Grassle, 1984) do not note the sexual phenotype of the maternal parent, it is possible that reports of variable sex ratios are due to different maternal parents.

Sex determination has been well-studied in only three other polychaete species; in a syllid, Brania clavata, in a dorviellid, Ophryotrocha puerilis, and in an archiannelid, Dinophilus gyrociliatus. Only in Dinophilus gyrociliatus is there any indication that sex determination is a digametic system. Traut (1970) reports a single univalent chromosome during metaphase I of spermatogensis and suggests males are the heterogametic sex. His result has been questioned since $D$. gyrociliatus, a gonochoric species, has highly dimorphic eggs (males arise from the smaller eggs), and has a sex ratio that is biased in favour of females. Sex ratio also shows geographical variation and depends not only on the maternal genotype but also environmental conditions Bacci, 1965; Traut, 1969a).

Earlier cytological work on $D$. gyrociliatus by Shearer (1912) suggests males contain only the maternal genome. However $D$. gyrociliatus is not 
Table 2 Summary of data and analysis of all crosses. In the Woods Hole crosses I, mortality was not noted while in all others it was. Female $\times$ male crosses are listed as $f \times m$; hemaphrodite $\times$ male crosses are listed as $h \times m$. Female and male offspring from $\mathrm{f} \times \mathrm{m}$ matings are noted as ff and $\mathrm{fm}$ while male offspring from $\mathrm{h} \times \mathrm{m} \mathrm{matings}$ are given as hm. Data were analysed as replicated goodness-of-fit tests using G statistics (Sokal and Rohlf, 1969). Observed counts were tested against an expected 50:50 sex ratio. Gp is pooled test and there is one degree of freedom in all tests. $G_{H}$ is the test of heterogeneity and degrees of freedom are the number of families minus one

\begin{tabular}{|c|c|c|c|c|c|c|}
\hline & \multirow{2}{*}{$\begin{array}{l}\text { Number } \\
\text { of } \\
\text { families }\end{array}$} & \multirow{2}{*}{$\begin{array}{l}\text { Per cent } \\
\text { of } \\
\text { females }\end{array}$} & \multirow{2}{*}{$\begin{array}{l}\text { Number } \\
\text { of } \\
\text { offspring }\end{array}$} & \multirow{2}{*}{$\begin{array}{l}\text { Per cent } \\
\text { of } \\
\text { mortality }\end{array}$} & \multicolumn{2}{|c|}{ G-Tests } \\
\hline & & & & & $\mathrm{G}_{\mathrm{P}}$ & $\mathrm{G}_{\mathrm{H}}$ \\
\hline \multicolumn{7}{|c|}{ Woods Hole crosses I } \\
\hline $\mathrm{h} \times \mathrm{m}$ & 31 & $3 \cdot 3$ & 3264 & $?$ & & \\
\hline $\mathrm{f} \times \mathrm{m}$ & 27 & $52 \cdot 9$ & 2110 & $?$ & $7 \cdot 06^{*}$ & \\
\hline \multicolumn{7}{|c|}{ Woods Hole crosses II } \\
\hline $\mathrm{h} \times \mathrm{m}$ & 13 & $2 \cdot 0$ & 297 & $9 \cdot 2$ & $353 \cdot 03^{*}$ & $19 \cdot 77$ \\
\hline $\mathrm{f} \times \mathrm{m}$ & 8 & $53 \cdot 0$ & 181 & $9 \cdot 5$ & 0.67 & $4 \cdot 30$ \\
\hline \multicolumn{7}{|c|}{ Crosses among offspring } \\
\hline $\mathrm{ff} \times \mathrm{hm}$ & 3 & $49 \cdot 3$ & 73 & $18 \cdot 9$ & $0 \cdot 01$ & $1 \cdot 11$ \\
\hline $\mathrm{ff} \times \mathrm{fm}$ & 3 & $50 \cdot 8$ & 67 & $26 \cdot 7$ & 0.01 & $8 \cdot 25$ \\
\hline \multicolumn{7}{|c|}{ New Jersey crosses } \\
\hline $\mathrm{h} \times \mathrm{m}$ & 3 & $0 \cdot 0$ & 48 & $36 \cdot 0$ & $66 \cdot 54^{*}$ & $0 \cdot 00$ \\
\hline $\mathrm{f} \times \mathrm{m}$ & 5 & $53 \cdot 4$ & 103 & $17 \cdot 6$ & 0.48 & $14 \cdot 93^{*}$ \\
\hline \multicolumn{7}{|c|}{ Reciprocal crosses } \\
\hline NJh $\times$ WHm & 5 & $0 \cdot 0$ & 217 & $0 \cdot 0$ & $300 \cdot 83^{*}$ & 0.00 \\
\hline $\mathrm{NJf} \times \mathrm{WHm}$ & 7 & $48 \cdot 2$ & 332 & $8 \cdot 3$ & 0.43 & $3 \cdot 16$ \\
\hline $\mathrm{WHh} \times \mathrm{NJm}$ & 3 & $0 \cdot 0$ & 112 & $8 \cdot 3$ & $157 \cdot 27^{*}$ & 0.00 \\
\hline WHf $\times$ NJm & 4 & $47 \cdot 7$ & 107 & $5 \cdot 8$ & 0.23 & 0.85 \\
\hline
\end{tabular}

* P less than $0 \cdot 05$.

a haplodiploid species since Shearer found that all eggs are fertilised, and that both males and females are diploid. The paternal set of chromosomes is lost in the development of male eggs, and the maternal copy doubles. Even so, Bacci (1965) believes sex in $D$. gyrociliatus is determined prior to fertilisation and is a polygenic trait.

Regardless of the mechanism of sex determination, the female-biased sex ratio in $D$. gyrociliatus is due to sibling competition and maternal control of sex ratio. Two lines of evidence from Shearer's (1912) and Traut's $(1969 a, b ; 1970)$ research support this view. First, matings occur before or at the time of hatching of worms from the egg cocoon. Male are mature at this time and mate with their immature sisters. Males have no gut and die within a day of hatching; females store the sperm until they reach maturity. Second, Traut (1969a) notes that under constant conditions the sex ratio is extraordinarily consistent; he suggests females can determine the type of egg. The data are consistent with Hamilton's (1967) predictions and the results of models developed by others (e.g., Bulmer and Taylor, 1980 a, $b$; Taylor, 1981) for female-biased sex ratios under conditions of sib mating. While development of egg type may be under maternal control it does not necessarily follow that sex determination is a polygenic trait.

In the two other species in which sex determination has been studied it is believed to be a polygenic trait. The evidence for Ophryotrocha puerilis is quite good. O. puerilis is a protandrous hermaphrodite in which older females can revert to males. Pure male and pure female lines have been selected for, and when these lines were crossed, the offspring were protandrous hermaphrodites (Bacci, 1965; 1978). In the other species, Brania clavata the evidence is not as clear-cut. $B$. clavata is a gonochoric species in which females can develop into "secondary" males but "primary" males never develop into females (Hauenschild, 1959). Crosses of primary male $\times$ females produce an average of 41 per cent males, and crosses of secondary males $\times$ females give 31 per cent males. Family sex ratios show considerable variation, and range from 0 per cent to over 50 per cent males (Hauenschild, 1959).

Overall, sex determination in polychaetes is poorly studied. Capitella species type I and Dinophilus seem to be good examples of simple sex determination. While sex in Ophryotrocha appears to be a polygenic trait, the evidence for 
Brania is equivocal. At this point it is not possible to make generalisations about sex determination in polychaetes.

The relationship between female heterogamety and hermaphroditism, as seen in Capitella type I, presents an interesting analogy to plant sexual systems. Phenotypically, Capitella type I is a mixture of males, hermaphrodites and female, a mixture which botanists call subdioecy. Charlesworth and Charlesworth (1978), in modelling the evolution of dioecy in plants, suggest two different mutants are required to change a hermaphroditic species into a dioecious species and point out that subdioecy and gynodioecy (species with female and hermaphrodite individuals) are transitions between a pure hermaphroditic species and separate sexes. If the two mutant genes are not linked, then populations will be a mixture of females, males and hermaphrodites. With female heterogamety there can be no linkage and thus establishment of separate sexes from a hermaphroditic ancestor may be very difficult (Charlesworth and Charlesworth, 1978). They also note hermaphrodites should be the more variable sex under female heterogamety. As predicted by Charlesworth and Charlesworth (1978), hermaphrodites in Capitella species type I show more variation in sexual phenotype than females (Petraitis, unpublished data).

Since the complex of sibling species of Capitella contains species with differential sexual systems, it is possible that the mixture of sexual phenotypes seen in Capitella type I could have arisen from either a purely hermaphroditic species or from a gonochoric species. If the ancestral species was hermaphroditic, it is possible the mixture of females, males, and hermaphrodites in Capitella type is an example of the situation envisioned by Charleworth and Charlesworth (1978) in which the establishment of separate sexes is quite difficult.

Acknowledgments I thank Anne Keeler, Rich Niesenbaum and Della Makower for their help with Capitella husbandry. This research was supported by the National Science Foundation (I)EB 82-13543).

\section{REFERENCES}

BAC:CI, (i. 1965. Sex Determination. Pergamon, Elmsford, N.Y.
BAC (1. G. 1978. Genetics of sex determination in Ophryotrocha (Annelida, Polychaeta). In Battaglia, B. (ed.) NATO Conf. Series IV, Marine Sciences, Vol. 2. pp. 549-571.

BULMIR, M. G. AND TAYLOR, P. D. 1980a. Dispersal and the sex ratio. Nature, 284, 448-449.

BULMER, M. (j. ANI) TAYLOR, P. D. $1980 \mathrm{~b}$. Sex ratio under the hay stack model. J. theor. Biol., 86, 83-89.

(CHARLESWORTH, B. AND CHARI.LSWORTH, D. 1978. A model for the evolution of dioecy and gynodioecy. Amer. Natur. $112,975-997$.

EDWARISON, J. R. 1970. Cytoplasmic male sterility. Bot. Rev., $36,341-420$.

(jANDFRS, F. R. 1978. The genetics and evolution of gynodioecy in Nemophilia menziesii. Can. J. Bot., 56, 1400-1408.

GHISELIN, M. T. 1969. The evolution of hermaphroditism among animals. Quart. Rev. Biol., 44, 189-208.

GRASSLE, J. F. AND GRASSI.F, J. P. 1976. Sibling species in the marine pollution indicator Capitella. Science, 192, 567-569.

GRASSLE, J. P. 1980. Polychaete sibling species. In Brunkhurst, R. O. and Cook, D. G. (eds.) Aquatic Oligochaete Biology, pp. $25-32$.

HAMILTON, W. 1). 1967. Fxtraordinary sex ratios. Science, 156, $477-488$.

HAUENSCHILD, C. 1959. Weiter Kreuzungsversuche zur Frage der Geschlechtsbestimmung bei dem Polychäten Grubea clavata. Z. Naturforsch., 14,89-92.

HOIBROOK, M. J. L. 1982. Hermaphroditism as a reproductive strategy in Capitella. MS thesis, Dalhousie University.

HOLBROOK, M. J. L. AND (iRASSI.E, J. P. 1984. The effect of low density on the development of simultaneous hermaphroditism in male (apitella species I (Polychaeta). Biol. Bull., 166, 103-109.

PITRAITIS, P. S. 1984. Laboratory experiments in the effects of a gastropod (Hydrobia totteni) on survival of an infaunal deposit-feeding polychaete (Capitella capitata, species type I). Marine Ecology Progress Series, 18, 263-268.

PETRAITIS, P. S. 1985 . Females inhibit males' propensity to develop into simultaneous hermaphrodites in Capitella species I (Polychaeta). Biol. Bull., in press.

SC:HROEDER, P. C. AND HERMANS, (: o. 1975. Annelida: Polychaeta. In Giese, A. C. and Pearse, J. S. (eds.) Reproduction of Marine Invertebrates, pp. 1-213.

SHEARER, C 1912. The problem of sex determination in Dinophilus gyrociliatus. Part 1. The sexual cycle. Quart. J. Micros. Sci., 57, 329-371.

SOKAL, R. R. AND ROHLF, F. J. 1969. Biometry. W. H. Freeman, San Francisco, Calif.

IAYIOR, P. D. 1981. Intra-sex and inter-sex siblings interactions as sex ratio determinants. Nature, 290, 64-66.

TENORE, K. R. 1977. Growth of Capitella capitata culture on various levels of detritus derived from different sources. Limm. \& Oceano., 22, 936-941.

TRAUT, w. 1969a. Zur Sexualität von Dinophilus gyrociliatus (Archiannelida). I. Der Einfluss von Aussenbedingungen und genetischen Faktoren auf des Geschlechtsverhältnis. Biol. Zentralbl., 88, 467-495.

TRAUT, W. 1969 b. Zur Sexualität von Dinophilus gyrociliatus (Archiannelida). II. Der Aufbau des Ovars und die Oogenese. Biol. Zentralbl., 88, 695-714.

TRAUT, W. 1970. Zur Sexualität von Dinophilus gyrociliatus (Archiannelida). III. Die Geschlechtsbestimmung. Biol. Zentralbl., 89, 137-161.

VAN DAMme, J. M. M. 1983. Gynodioecy in Plantago lanceolata L. II. Inheritance of three male sterility types. Heredity, $50,253-273$. 